\title{
ESCOLA E COMUNIDADE: SABERES E PRÁTICAS NA CONSTRUÇÃO DA CIDADANIA
}

\author{
Rosangela Costa Soares ${ }^{1}$ \\ José Cláudio Rocha
}

\section{Resumo:}

Este artigo resulta de uma pesquisa sobre a relação entre sociedade civil e Estado, apresentando o processo histórico das lutas populares pelo direito à educação básica, empreendidas pelos moradores de um bairro da periferia de Salvador, Bahia, entre os anos de 1970 a 2016. Teve como objetivo compreender como a escola, fruto dessas lutas, se articulou com as instituições do bairro para a construção do Plano de Ação da Escola em Educação em Direitos Humanos. Tratou-se de um estudo qualitativo, fundamentado na proposta de Educação Dialógica formulada por Freire (2015) em consonância com a pesquisa-ação e o Design-Basead Reserch. Concluímos que o diálogo sobre práticas educativas valoriza a complexidade da relação escola e comunidade local, para que na tensão diária e no confronto das disputas, possamos construir conhecimentos que valorizem os sujeitos, suas histórias, sua comunidade.

Palavras-chave: Direito à Educação. Participação. Educação em Direitos Humanos.

\begin{abstract}
This article results from a research on the relationship between civil society and the State, presenting the historical process of popular struggles for the right to basic education, undertaken by residents of a neighborhood in the outskirts of Salvador, Bahia, between 1970 and 2016. It has as an objective to understand how the school, fruit of these struggles, articulated with the institutions of the neighborhood for the construction of the Plan of Action of the School in Education in Human Rights. It was a qualitative study, based on the proposal of Dialogical Education formulated by Freire (2015) in consonance with action research and Design-Basead Reserch. We conclude that the dialogue on educational practices values the complexity of the relationship between school and local community, so that in the daily tension and confrontation of disputes, we can build knowledge that values the subjects, their stories, their community.
\end{abstract}

Keywords: Right to education. Participation. Education in Human Rights.

\footnotetext{
${ }^{1}$ Mestre em Gestão e Tecnologias Aplicadas à Educação pela Universidade do Estado da Bahia. Membro do Centro de Referencial em Desenvolvimento e Humanidades - UNEB. E-mail: rosacsoares.2018@ gmail.com

${ }^{2}$ Professor titular da UNEB; Professor permanente dos Programas de Pós-Graduação GESTEC, DMMDC e PROFNIT; Coordenador do Centro de Referência em Desenvolvimento e Humanidades - UNEB; jrocha@uneb.br
} 
Estudar a relação entre sociedade e Estado, representada pelos movimentos sociais e a escola, demonstra a possibilidade de revelar saberes e práticas sociais construídos no interior da comunidade, dos sentidos atribuídos a luta pela moradia, pela educação e por melhores condições de vida.

Desse modo, busca-se mostrar neste artigo o processo de construção do Plano de Ação da Escola em Educação e Direitos Humanos, parte integrante do trabalho de conclusão de curso do Programa de Pós-Graduação em Gestão e Tecnologias Aplicadas à Educação (GESTEC) em parceria com o Centro de Referência em Desenvolvimento e Humanidades (CRDH), ambos vinculados a Universidade do Estado da Bahia (UNEB) e de instituições governamentais e não governamentais localizados em um bairro da periferia de Salvador, Bahia.

Cabe destacar que o referido Plano é resultado do desenvolvimento de processos metodológicos participativos e colaborativos. Para tanto, utilizamos linguagens e materiais pedagógicos contextualizados com a realidade local, além de relacionar aspectos da prática dialógica, da gestão democrática da escola pública e do respeito as diversidades. Dimensões presentes nas no Plano Nacional de Educação em Direitos Humanos (PNEDH) aprovado em 2007.

Nas seções seguintes apresentamos a construção do projeto "Saramandaia, Território de luta e resistência: diálogo entre a escola e comunidade" construído com base no estudo de caso sobre a participação dos movimentos sociais na luta pelo direito à educação básica em Saramandaia, bairro da periferia de Salvador, onde foi abordado o surgimento do bairro e o processo de luta dos moradores junto à Prefeitura para a construção da primeira escola na localidade.

\section{Metodologia}

A metodologia aplicada buscou implantar uma ação por parte dos sujeitos implicados no problema sob observação (THIOLLENT, 2011, p. 21), a partir da metodológica da Abordagem Baseada em Direitos (ABD) articuladas com as técnicas da pesquisa-ação (ROCHA, 2016).

Conforme, Rocha (2016, p.81) as metodologias de pesquisa emancipatórias como o Right-Based Approach (RBA) ou Abordagem Baseada em Direitos contribuem para a difusão 
do conhecimento e para formação de uma cultura de respeito e promoção dos Direitos Humanos. Ainda de acordo com o autor:

[...] a $R B A$ é uma estratégia utilizada por Agências Multinacionais, ONGs, Institutos de pesquisa e Universidades para efetivar o direito humano ao desenvolvimento sustentável, mas também para desenvolver projetos de pesquisa aplicada e extensão em direitos humanos ou que tragam em seu bojo preocupações com a cidadania. (ROCHA, 2016, p. 93)

Assim, foi possível a articulação dialógica entre a unidade de ensino e as diferentes instituições atuantes no bairro para a construção coletiva do plano de ação da escola em Educação em Direitos Humanos (EDH), tendo como objetivo reconhecer o papel estratégico entre educação escolar e Direitos Humanos no contexto comunitário.

Nesse horizonte, na fase inicial desse estudo, apresentamos a proposta de trabalho e o levantamento das dificuldades relacionados a interação entre a escola e comunidade local ou externa: a) a comunidade escolar não conheciam a história do bairro; b) a comunidade escolar não conhecia o processo de luta dos moradores que levou a construção da escola; d) o trabalho da escola pouco dialogava com o trabalho realizado pelos movimentos sociais do bairro.

Dessa forma, organizamos as informações por dimensão e, a seguir, apresentadas as expectativas prioritárias para formulação dos temas. Um: desconhecimento da história do bairro; dois: desconhecimento do processo de construção da escola. Três e último: dificuldade de integração entre Escola, famílias e comunidade local.

Essas foram as questões que justificaram a escolha do tema e nos direcionaram a pensar: como a escola pode reconfigurar o seu papel dentro de uma comunidade e estabelecer relação com seu entorno?

Apoiados neste questionamento trouxemos como objetivo geral investigar como ocorre o processo de mobilização entre a escola e as instituições do bairro de Saramandaia na promoção do diálogo interinstitucional sobre práticas educativas voltadas para garantia e defesa dos Direitos Humanos.

Vale ressaltar que tal proposta, para ser coerente deve fundamentar-se nos objetivos e princípios da EDH e em uma concepção progressista de educação, perpassando por todos os níveis de ensino e áreas do conhecimento, adequando-se as diferentes faixas etárias e níveis de compreensão dos sujeitos envolvidos no processo educativo.

Dessa forma, realizamos três seminários (THIOLLENT, 2011). O primeiro, com a equipe gestora, onde adequamos o projeto à realidade da escola. $\mathrm{O}$ segundo, com base na avaliação feita pelos educandos e instituições participantes, estruturamos as oficinas temáticas 
denominadas Rodas de Conversa em referência ao "círculo de cultura" de Freire (2015), espaços em que:

[...] não se ensina, aprende-se em reciprocidade de consciências; não há professor, há um coordenador, que tem por função dar as informações solicitadas pelos respectivos participantes e propiciar condições favoráveis à dinâmica do grupo, reduzindo ao mínimo sua intervenção direta no curso do diálogo. (FREIRE, p. 2015 p.6)

No terceiro e último seminário, avaliamos os encontros, apontando as dimensões a serem incluídas no Plano de Ação da Escola em Educação e Direitos Humanos. A seguir apresentamos a síntese das Rodas de Conversa realizadas em parceria com a escola, famílias, grupos culturais e instituições do bairro e a proposta do Plano de Ação da Escola de Educação em Direitos Humanos.

\section{Rodas de conversa: potencializando o trabalho educativo}

A primeira Roda de Conversa articulou o aspecto lúdico ao trabalho voltado para a construção da cidadania com atividades em que o educando era estimulado a compartilhar sua história, sua relação no ambiente doméstico, escolar e comunitário. Depois das produções, solicitamos que os educandos apresentassem aos colegas.

Por meio dessa atividade compreendemos como os educandos percebem os problemas que afligem o bairro em que moram: falta de saneamento básico e infraestrutura; alto índice de violência; falta de assistência à saúde; ausência de áreas de lazer. Mas, quando perguntados como é Saramandaia, todos afirmaram que é um lugar bonito, demonstrando o aspecto afetivo entre eles e a comunidade.

Neste horizonte, Campos (2012) afirma que o trabalho educativo deve partir da história de vida, da formação familiar e comunitária dos educandos "[...] o direito à identidade, além de compreender o direito a um nome, à nacionalidade e às relações familiares, abrange aspectos mais amplos ligados à identidade cultural" (CAMPOS, 2012, p. 40), sendo o ponto de partida do trabalho educativo em direitos humanos.

A segunda Roda de Conversa contou com a exibição do documentário, Retalhos: A Memória Viva de Saramandaia, contemplado pelo edital Comunica Diversidade do Ministério da Cultura (MinC), produzido por Lúcio Lima, cineasta, ator e morador do bairro.

Conforme Lúcio Lima: 
[...] Retalhos narra as memórias afetivas e uma comunidade na fala do menino Emerson Almeida e seu sonho de levar o nome de Saramandaia ao mundo através da arte circense. Nos traços do grafiteiro Thito Lama, que desenha e canta os males sociais servindo de exemplo e alertando os jovens da comunidade. E na sabedoria ancestral do Sr. Armandio, um dos moradores mais antigos do bairro que ainda mostra a lucidez necessária para conduzir Saramandaia para novas conquistas.

Acreditamos que o estudo da história da comunidade de pertencimento permite a construção de bases para a inserção em contextos coletivos e a percepção do indivíduo como pertencente a um grupo social com características, memórias e histórias próprias.

Após a exibição do documentário, Lúcio Lima respondeu às perguntas dos educandos e contou sua trajetória profissional iniciada no grupo de teatro da igreja do bairro até ser protagonista e diretor de filmes.

Retalhos, além de mostrar a história de Saramandaia, trouxe para a Roda de Conversa a discussão sobre o direito que a criança e adolescente têm à cultura, informação, lazer, esportes, diversões, espetáculos e produtos e serviços que respeitem sua condição peculiar de pessoa em desenvolvimento (BRASIL, 1990).

Contudo, o reconhecimento constitucional de tais direitos, não garante o acesso de crianças e jovens das classes populares à cultura, lazer e esporte, daí a relevância do trabalho realizado pelos grupos culturais e instituições de Saramandaia na promoção desses direitos.

Na terceira Roda de conversa foi exibido o documentário "Saramandaia existe" produzido pelo Grupo de Pesquisa Lugar Comum vinculado a Faculdade de Arquitetura da Universidade Federal da Bahia (FAUFBA), com o objetivo de analisar os impactos causados na comunidade em decorrência da construção da Via Expressa Linha Viva. De acordo com a professora Ana Fernandes, coordenadora do Lugar Comum, a proposta do vídeo é tornar a comunidade visível no debate atual e impedir que ela seja esquecida pelos órgãos públicos.

$\mathrm{Na}$ ocasião foram discutidas as ações realizadas pelas associações de moradores e grupos culturais de Saramandaia junto ao Estado para que o bairro não seja afetado com a construção do Projeto Linha Viva. Em seguida, os pesquisadores e estudantes da Faculdade de Arquitetura da UFBA apresentaram o Projeto da Praça de Saramandaia, conquistada pelos moradores como compensação dos impactos causados pelo empreendimento Horto Bela Vista.

O emprego dos termos favela, periferia, comunidade e subúrbio também foram debatidos na Roda de Conversa. Neste momento os estudantes realizaram várias perguntas, demonstrando interesse pela discussão. Para finalizar o encontro, o Grupo apresentou o mapa 
do bairro, a maquete e o projeto da praça, elaborado em parceria com os moradores, que será construída próxima a escola.

Na quarta Roda de Conversa, para além dos muros da escola, contou com a outra da escola municipal da comunidade, localizada em frente à escola pesquisada, embora estejam tão próximas e sejam da mesma rede de ensino, não verificamos atividades pedagógicas e formativas entre as duas instituições.

Por isso, propomos que as equipes gestoras desenvolvessem atividades que envolvessem os educandos das duas escolas. Como estávamos no mês de novembro, mês dedicado à reflexão sobre a luta, a resistência e a conquista da população negra do Brasil, escolhemos o dia 20 de novembro para realizar a ação conjunta.

Cada escola ficou responsável por planejar e produzir atividades referentes ao Dia da Consciência Negra e expor para visitação da comunidade além dos trabalhos de artes plásticas, apresentações de poesias pelos estudantes, cartazes e coreografias de músicas de valorização da cultura negra.

Segundo as Diretrizes Curriculares Nacionais (2013), o ambiente educacional promotor da Educação em Direitos Humanos deve considerar a educação como processo de interação da experiência pessoal e coletiva.

[...] trata-se de um processo que se recria e se reelabora na intersubjetividade, nas vivências relações dos sujeitos, na relação como meio ambiente, nas práticas pedagógicas e sociais do cotidiano e nos conflitos sociais, constituindo-se, assim, num modo de orientação e condução da vida. (BRASIL, 2013, p. 524)

A vivência da EDH possibilita o desenvolvimento, a socialização, a formação ética dos sujeitos, através do enfrentamento dos preconceitos e discriminações. Sob esta perspectiva, promover práticas de interação entre instituições, além de criar um ambiente rico em trocas de experiências, também é gerador de processos inovadores de ensinoaprendizagem.

No campo educacional a inclusão da temática afro-brasileira e África no currículo escolar é uma conquista dos movimentos sociais, principalmente do movimento negro, que, no exercício da cidadania, se organizaram e reivindicaram reparação e reconhecimento de sua importância na história política e social brasileira.

O Projeto Arte Consciente mediou a quinta Roda de conversa, apresentando o trabalho que realiza com crianças e jovens de Saramandaia como forma de combate à violência e a prevenção do uso de drogas. Formado a partir de um grupo de jovens nascidos na comunidade, 
o Projeto atende 200 crianças e jovens de 7 a 21 anos em oficinas de percussão afro-brasileira, artes circenses, dança, capoeira, boxe e grafite. Conforme Antônio Marcos, um dos fundadores do projeto:

[...] nossa missão é preparar pessoas para a vida, ensinando não apenas arte, mas princípios de cidadania, convivência e respeito. Para isto, oportunizamos atividades educativas e artísticas que promovam o exercício da cidadania de forma consciente.

Assim, além do Projeto Arte Consciente, o bairro conta com duas escolas comunitárias destinadas a educação infantil, a Fundação Cidade Mãe, instituição municipal, que oferece cursos de artes plásticas, capoeira, dança, artesanato e informática, o grupo de teatro coordenado por Lúcio Lima; o grupo de hip-hop constituído por ex-alunos da escola, a Associação dos Moradores de Saramandaia que realiza um trabalho de educação ambiental com os moradores.

As diferentes práticas educacionais, esportivas e culturais existentes no bairro revelam a diversidade de grupos e instituições preocupados em oferecer condições necessárias para inclusão social dessa população.

A sexta e última Roda de Conversa ocorreu em 17 de dezembro de 2015, no salão da Fundação Cidade Mãe, toda a Escola e comunidade local se mobilizaram para o encerramento do projeto. Foi um momento de apresentar as produções dos educandos e de mostrar que é possível realizar um trabalho integrado entre escola e comunidade, através da instauração de espaços de debates, análises de propostas, encaminhamentos e acompanhamentos de ações.

Formar para e em Direitos Humanos implica promover metodologias participativas que despertem nos educandos autonomia, criatividade e novas descobertas, abrindo-lhes novos horizontes de expectativa. Dessa forma, foi possível integrar atividades de sala de aula e preparar o ambiente escolar aos temas do projeto. Isto demandou dos docentes e da coordenação pedagógica um trabalho de pesquisa primoroso, que foi desde a seleção de textos a produções artísticas.

Outro ponto que merece destaque foi o envolvimento das famílias na produção e acompanhamento das ações. Os pais e responsáveis abraçaram o entusiasmo das crianças e adolescentes, proporcionando os meios materiais para a produção dos trabalhos, além de permitirem a presença dos estudantes nos ensaios das coreografias. 


\section{Resultados e discussões}

A análise dos registros produzidos pelos educandos, equipe gestora, professores, funcionários, famílias e instituições do bairro, durante o Projeto Saramandaia, Território de Luta e Resistência: Diálogo entre Escola e Comunidade possibilitou uma ampla discussão sobre a necessidade de articulação entre a comunidade escolar e local.

A gestão da escola demonstrou interesse em se aproximar das famílias e da comunidade, trazendo para o espaço escolar o diálogo o cotidiano da comunidade, segundo a proposta de Paulo Freire (2015), na perspectiva da prática dialógica, em que o diálogo é uma exigência existência e a palavra o resultado radical entre ação e reflexão (FREIRE, 2015, p. 109).

Durante as etapas do projeto, identificamos como a equipe gestora encaminhou a mobilização, que ações priorizaram e como respondeu às demandas da comunidade. Ao analisar as atividades com os educandos na produção das atividades em sala de aula e as Rodas de Conversa, identificamos a base do trabalho coletivo entre a escola e comunidade de pertencimento, prática dialógica e a gestão democrática. Para isto, selecionamos algumas falas dos sujeitos envolvidos no projeto, bem como recortes de atas e relatórios feitos pelo CRDH que identificassem a estreita relação entre gestão democrática e prática dialógica.

[...] A escola precisa ser viva. Um espaço de trocas com a comunidade. O nosso papel enquanto educadores é formar cidadãos, assim, nosso aluno perceberá que tudo que a escola ensina ele vai utilizar lá fora, na vida. (GESTORA1)

[...] eu não sabia que em Saramandaia tinha tantas instituições atuantes na defesa dos direitos das crianças e adolescentes. Nós precisamos nos conhecer melhor e articular nosso trabalho. (GESTORA 2)

$\mathrm{Na}$ fala de uma das integrantes da equipe gestora percebemos a preocupação da Escola em articular a prática educativa à realidade social dos educandos. Embora, não tenhamos percebido a efetiva atuação das famílias e das instituições locais na construção do Projeto Político-Pedagógico e no Conselho Escolar.

Para, Bordignon e Gracindo (2011), autores que debatem gestão da escola da pública “[...] a participação e compromisso não se referem apenas a comunidade interna, mas devem buscar alianças com a comunidade externa, a quem a escola serve e pertence efetivamente, promovendo a cooperação interinstitucional" (BORDIGNON; GRACINDO, 2011, p. 171). 
Os autores também destacam que a autonomia para ser duradoura deve ser conquistada, não oferecida institucionalmente.

Assim, a participação comunitária tem o papel de democratizar a educação, através do diálogo entre todos os sujeitos envolvidos direta e indiretamente no processo educativo: equipe gestora, professores, funcionários, aluno, família e comunidade. Entretanto, Freire (2014) nos alerta para o fato de que democratizar a educação no Brasil não é uma tarefa fácil, pois, continuamos submersos em uma tradição autoritária, promotora de práticas excludentes que desqualifica o conhecimento e a voz do povo.

[...] um maior nível de participação democrática dos alunos, dos pais, da [comunidade local], de uma escola que, sendo pública, pretende ir tornando-se popular, demanda estruturas leves, disponíveis à mudança, descentralizadas que viabilizem, com rapidez e eficiência, a ação governamental. (FREIRE, 2014, p. 88, grifo nosso)

Essas considerações formuladas por Freire (2014) referem-se à participação como responsabilidade de todos, comunidade escolar e local, tendo o conselho Escolar como espaço de diálogo e ações voltadas para resolução de problemas e melhoria da qualidade do ensino.

[...] democratizar o poder, reconhecer o direito de voz aos alunos, às professoras, diminuir o poder pessoal das diretoras, criar instâncias novas de poder com os Conselhos de Escola, deliberativo e não apenas consultivo e através dos quais, num primeiro momento, pais e mães ganhassem ingerência nos destinos da escola de seus filhos; num segundo momento, esperamos, é a própria [comunidade local] que tendo a escola como algo seu, se faz igualmente presente na condução da política educacional da escola. (FREIRE, 2014, p. 87, grifo nosso)

Uma vez reconhecida a relevância do trabalho coletivo entre escola e comunidade, buscamos a fala das lideranças comunitárias sobre o papel da escola para a comunidade de Saramandaia:

[...] acho que a escola tem um papel muito importante porque é o lugar onde recebe as demandas, pais, professores e funcionários. É um lugar onde vivencia o cotidiano da comunidade como também é um lugar onde as informações circulam. As questões que aparecem lá são discutidas lá ou escapam para outros espaços do bairro, onde não necessariamente a gente alcançaria. (LÍDERANÇA 6)

[...] a escola tem esse papel de troca, de aprendizado, de suscitar a discussão de direitos que pouco chega as pessoas das classes populares. (LIDERANÇA 6) 
[...] a escola tem que se aproximar da comunidade para entender o aluno que tem. (LÍDER COMUNITÁRIO 7)

[...] trabalhar em parceria com a escola é uma forma de conseguir promover esse diálogo e construir uma relação com a comunidade. (LIDERANÇA COMUNITÁRIA 4)

As reflexões acima indicam que as ações educativas entre escola e comunidade devem fazer parte do cotidiano escolar, estando presentes no Projeto Político-Pedagógico e Conselho Escolar, além de aproximar a escola do contexto social do educando. As escolas dos bairros empobrecidos são importantes canais de difusão do conhecimento, experiências e reflexões sobre as questões que atingem a comunidade, facilitando a construção de uma rede colaborativa.

Dessa forma, o Plano de Ação da Escola em Educação em Direitos Humanos Saramandaia, Território de Luta e Resistência: Diálogo entre a Escola e Comunidade, construído com a participação da comunidade escolar e as instituições do bairro, pretende constituir-se em um plano referência para apoiar, fortalecer e aproximar práticas educativas em Direitos Humanos e formação para cidadania, além de subsidiar a elaboração e execução de ações interinstitucional.

Finalmente, ressaltamos que os temas e os procedimentos utilizados neste projeto são uma das muitas possibilidades da prática educativa, seja do tema, seja da ação em questão. Espera-se, inclusive que cada comunidade escolar, faça adequações, no intuito de atender às especificidades de sua realidade.

\section{Considerações finais}

Diante do exposto, retornemos a questão inicial: como se mobiliza a escola na promoção do diálogo interinstitucional sobre práticas educativas que assegurem o reconhecimento da história da comunidade de Saramandaia na luta, conquista e defesa do direito à educação?

Com base nas sistematizações do conjunto de evidências encontradas em campo e também a partir do aporte teórico apresentou-se algumas trilhas sobre a importância do 
diálogo interinstitucional sobre práticas educativas entre escola e comunidade local que assegurem a formação para cidadania e para a Educação em Direitos Humanos.

Ficou evidenciado que as especificidades de cada comunidade determinam o método de abordagem que deve ser aplicado na construção do plano de ação da escola, todavia, existem pontos em comum que devem ser levados em consideração no momento do planejamento das ações.

Primeiro, um arcabouço teórico alicerçado na prática dialógica, na gestão democrática da escola pública e no respeito às diversidades. Segundo, o reconhecimento e fortalecimento de experiências que explorem a criação de espaços de diálogos sobre o conhecimento produzido pela comunidade de pertencimento da escola e o currículo escolar.

Acrescentamos que as discussões ocorridas no Centro de Referência em Desenvolvimento e Humanidades foram fundamentais para a compreensão da importância do tema como forma de conquista de direitos e criação de espaços de diálogos voltados para a construção dos processos socioeducativos capazes de valorizar as singularidades da comunidade, sua constituição e identidade.

Para tal, o estudo considerou a relevância da pesquisa como um dos pilares da construção do conhecimento em sua relação com o sujeito histórico. Não podemos desvincular a historicidade, o compromisso político e ético da escola na construção dessas dimensões, bem como a necessidade de intervenção.

Afinal, Paulo Freire nos ensina que a utopia enquanto ato de denunciar a sociedade naquilo que ela tem de desumano e enquanto ato de anunciar uma sociedade mais justa e igualitária. Nesse veio, anunciar e denunciar são utopias. Nossa ação enquanto educadores comprometidos com a formação política das comunidades nas quais exercermos nosso trabalho deve contribuir para formar seres humanos que sonhem e busquem uma sociedade justa, transformadora, humanizada.

Finalmente, esperamos ter conseguido demonstrar que a articulação da Escola com a comunidade local é o produto de uma postura política refletida no trabalho da comunidade escolar e local.

\section{REFERÊNCIAS}

BORDIGNON, G.; GRACINDO, R. V. Gestão da educação: o município e a escola. In: FERREIRA, N. S. C.; AGUIAR, M. A. S. (orgs.). Gestão da educação: impasses, perspectivas e compromissos. 8 ed. São Paulo, Cortez, 2011. 
BRASIL. Estatuto da criança e do adolescente: Lei federal nº 8069, de 13 de julho de 1990. Rio de Janeiro: Imprensa Oficial, 2002.

BRASIL. Ministério da Educação. Secretaria de Educação Básica. Diretoria de Currículos e Educação Integral. Diretrizes Curriculares Nacionais Gerais da Educação Básica: Brasília, 2013.

BRASIL. Comitê Nacional de Educação em Direitos Humanos. Plano Nacional de Educação em Direitos Humanos: 2008. Brasília: Secretaria Especial de Direitos Humanos, 2008.

CAMPOS, H. G. A história e a formação para a cidadania nos anos iniciais do ensino fundamental. São Paulo: Saraiva, 2012.

FREIRE, P. Pedagogia do oprimido. Rio de Janeiro: Paz e Terra, 2015.

FREIRE, P. Política e educação. Rio de Janeiro: Paz e Terra, 2014.

MATTA, A. E. R; ROCHA. J. C. (Orgs.). Cognição: aspectos contemporâneos da construção e difusão do conhecimento. Salvador: EDUNEB, 2016.

THIOLLENT, M. Metodologia de pesquisa-ação. São Paulo: Cortez, 2011. 